\title{
Socio-economic indicators are independently associated with intake of animal foods in French adults
}

\author{
Caroline Méjean ${ }^{1, *}$, Wendy Si Hassen ${ }^{1}$, Christelle Lecossais ${ }^{1}$, Benjamin Allès ${ }^{1}$, \\ Sandrine Péneau', Serge Hercberg ${ }^{1,2,3}$ and Katia Castetbon ${ }^{2,4}$ \\ 'Université Paris 13, Sorbonne Paris Cité, Equipe de Recherche en Epidémiologie Nutritionnelle (EREN), Centre \\ d'Épidémiologie et Statistiques Paris Nord, Inserm (U1 153), Inra (U1 125), Cnam, Université Paris 5, Université Paris \\ 7, F-93017 Bobigny, France: ${ }^{2}$ Université Paris 13, Sorbonne Paris Cité, Unité de Surveillance et d'Épidémiologie \\ Nutritionnelle (USEN), SMBH Paris, Bobigny, France: ${ }^{3}$ Department of Public Health, Hôpital Avicenne, Bobigny, \\ France: ${ }^{4}$ Université Libre de Bruxelles, Ecole de Santé Publique, Centre de Recherche en Épidémiologie, \\ Biostatistiques et Recherche Clinique, Bruxelles, Belgium
}

Submitted 11 December 2015: Final revision received 28 April 2016: Accepted 23 May 2016: First published online 4 July 2016

\begin{abstract}
Objective: The specific role of major socio-economic indicators (education, occupation, income) in influencing consumer choice of animal foods (AF) intake could reveal distinct socio-economic facets, thus enabling elucidation of mechanisms leading to social inequalities in health. We investigated the independent association of each indicator with intake of different AF and their effect modification.

Design: Cross-sectional study. AF intake was estimated using three $24 \mathrm{~h}$ dietary records. Associations between socio-economic factors and AF intake and interactions between socio-economic indicators were assessed using ANCOVA adjusted for age and energy intake. Analyses were performed separately for men and women, since gender interactions were found.

Setting: France.

Subjects: Adults ( $n$ 92036) participating in the NutriNet-Sante Study.

Results: Low educated persons had higher intake of red meat (+9-12 g/d), processed meat ( $+6-9 \mathrm{~g} / \mathrm{d}$ ) and poultry (for men, $+7 \mathrm{~g} / \mathrm{d}$ ) than those with a higher education level. Percentage of fish consumers was lower in individuals of the lowest income class compared with those in higher classes. Manual workers had a higher intake of cream desserts (for men, $+14 \mathrm{~g} / \mathrm{d}$ ) than managerial staff. Few significant interactions were found. In stratified analyses, persons with the highest income consumed more yoghurt than those who had lower income, only in low educated individuals.

Conclusions: Socio-economic disparities in AF intake varied according to the socio-economic indicator, suggesting the specific influence of each indicator on $\mathrm{AF}$ intake. In particular, lower education was associated with higher intake of red and processed meats and cream desserts, and had an effect modification on the relationship between income and $\mathrm{AF}$ intake.
\end{abstract}

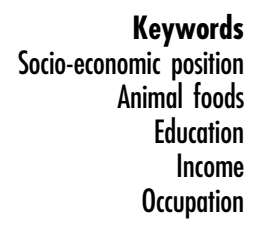

Evidence concerning the nutritional value of animal foods (AF) is sometimes contradictory, leading to opposing effects on chronic diseases such as cancer and CVD ${ }^{(1,2)}$. $\mathrm{AF}$ are rich sources of high-quality proteins, vitamins and minerals, including bioavailable Fe, vitamin D, Zn, Ca and vitamin $\mathrm{B}_{12}{ }^{(3)}$; intake of healthy $\mathrm{AF}$ such as low-fat fish and milk decreases the risk of colorectal cancers, high blood pressure and $\mathrm{CVD}^{(1,4-7)}$. In contrast, high intake of unhealthy $\mathrm{AF}$ rich in fat and $\mathrm{Na}$, such as processed and red meat and cheese, has been shown to increase the risk of CVD and colorectal cancer ${ }^{(1,2,5)}$.
Dietary factors may contribute substantially to explaining the impact of socio-economic position (SEP) on mortality and morbidity related to chronic diseases (up to $66 \%)^{(8-10)}$, underlining the importance of socio-economic disparities in diet. Evidence is mounting that a high SEP, as defined by high education level, high income and high occupational category, is consistently associated with healthy dietary patterns, including greater consumption of fruits, vegetables and whole-grain foods ${ }^{(11-13)}$. SEP is the product of a number of social and economic factors; the relationship between each of the three major 
socio-economic indicators (education, occupation and income) with dietary intake may be independent of the two other socio-economic factors ${ }^{(13,14)}$. As underlined by Galorbardes et ll $^{(13)}$, the three socio-economic indicators are weakly correlated, since they represent different concepts ${ }^{(15,16)}$. They should therefore be taken into account simultaneously ${ }^{(17)}$ and interactions between them should be examined to better understand their importance in terms of diet. For AF, each SEP indicator may be independently associated with intake. Income probably influences intake of expensive AF through a direct effect on financial resources, while knowledge and skills attained through education may make individuals more receptive to health education messages concerning AF intake ${ }^{(16)}$. Occupation reflects social standing and could be related to intake of some AF because of social networks ${ }^{(13)}$.

Although numerous studies on the association between SEP and the intake of different groups of AF have been conducted, few of them have examined the independent effect of socio-economic indicators ${ }^{(13,18-22)}$. They showed that findings were not systematically concordant with those of studies using a single SEP. For instance, when adjusted for occupation or income, education was not associated, or was inversely associated, with cheese intake ${ }^{(20,22)}$, while a large majority of studies using only one SEP indicator showed higher cheese intake among individuals with higher socio-economic status. In contrast, significant associations remained after adjustment for other SEP indicators, such as positive associations between income, education or occupation and intake of fish and poultry $^{(11,20,21)}$. Only one study simultaneously used the three socio-economic indicators, but low-fat milk was the sole AF assessed ${ }^{(18)}$. Study of the relationship between intake of $\mathrm{AF}$ and socio-economic indicators is useful for elucidating mechanisms leading to social inequality in health, since intake of diverse AF may differentially influence the onset of major chronic pathologies.

The aim of our study was to assess the independent cross-sectional associations of each major socio-economic factor (education, occupation and income) with the intake of multiple AF groups. In addition, the effect modification of each socio-economic indicator upon associations between the other two SEP indicators and AF intake was investigated.

\section{Methods}

\section{Population}

Our sample was composed of 92036 individuals who were participants in the NutriNet-Santé Study, a large web-based prospective cohort launched in France in May 2009, with a scheduled follow-up of 10 years. It was implemented in a general population targeting Internetusing adult volunteers aged 18 years or older. The study was designed to investigate the relationship between nutrition and health, as well as determinants of dietary behaviour and nutritional status. The design, methods and rationale have been described previously ${ }^{(23)}$. Briefly, in order to be included in the cohort, participants had to fill in an initial set of questionnaires assessing dietary intake, physical activity, anthropometry, lifestyle and socioeconomic conditions, along with health status at baseline.

\section{Data collection}

All data used in the present study were collected at baseline.

Socio-economic position and demographic characteristics SEP of participants was assessed at baseline by three indicators: education, income and occupation, using categories consistent with the French National Institute of Statistics' definitions $^{(24)}$. If participants were unemployed or retired, we noted the occupational category of their last job. Participants were asked their monthly household income, including salary, social benefits, family allowance and rental income. To assess educational level, participants gave their highest attained diploma. Demographic factors included gender, age, marital status, place of residence, and presence of children in the household.

Educational level was recoded into four categories according to the distribution throughout the entire sample: primary education, secondary education, undergraduate (corresponding to up to 3 years after the high-school diploma) and postgraduate (more than 3 years after the high-school diploma). Occupation was recoded into six classes: manual worker, employee, intermediate profession (technician, skilled employee, teacher, nurse, etc.), managerial staff, self-employed (craftsman, shopkeeper, company manager, farmer) and never employed (homemaker, student, disabled). Household income per month was calculated by household units. One household unit was attributed for the first adult in the household, 0.5 for other persons aged 14 years or older and 0.3 for children under 14 years $^{(25)}$. Categories used for monthly income were the following: $<1200 €, 1200-1800 €, 1800-2700 €$ and $>2700 €$ per household unit, plus a category for individuals who were unwilling to answer.

\section{Dietary intake assessment}

At baseline, participants were invited to provide three random validated $24 \mathrm{~h}$ dietary records during a 2 -week period (one weekend day and two weekdays) ${ }^{(23)}$. The dietary record is completed via an interactive interface and is designed for self-administration on the Internet ${ }^{(26)}$. The web-based dietary assessment method relies on a meal-based approach, recording all foods and beverages (type and quantity) consumed at breakfast, lunch, dinner and all other eating occasions. First, the participant fills in the names of all food items eaten. Next, he/she estimates portion sizes for each reported food and beverage according to standard measurements (e.g. home containers, grams indicated on the package) or using 
images available via the interactive interface. These photographs, taken from a validated illustrated booklet ${ }^{(27)}$, represent more than 250 foods (corresponding to 1000 generic foods) served in seven different portion sizes. A study investigating the validity of our web-based selfreported dietary record tool with respect to $24 \mathrm{~h}$ urinary and plasma biomarkers showed that the web-based dietary record tool used in the NutriNet-Santé Study performs well at estimating protein ( 0.61 in men, 0.64 in women) and $\mathrm{K}(0.78$ in men, 0.42 in women) intakes (intra-cluster correlation coefficients), and fairly well at estimating fruits and vegetables (correlation with plasma $\beta$-carotene: 0.35 in men and 0.41 in women), fish (correlation with plasma DHA+EPA: 0.51 in men and 0.54 in women), $\beta$-carotene ( 0.37 in men, 0.38 in women), vitamin C ( 0.58 in men, 0.32 in women), $\mathrm{Na}(0.47$ in men, 0.37 in women) and $n$-3 fatty acid intakes $(0.36$ in men, 0.38 in women; Spearman correlation coefficients) ${ }^{(28,29)}$. In addition, a pilot study comparing our web-based $24 \mathrm{~h}$ recording tool with a dietitian's interview showed strong agreement between the two methods, particularly for AF intake ${ }^{(26)}$.

Values for energy were estimated using published nutrient databases ${ }^{(30)}$ and were completed for recent market foods and recipes. Foods were classified according to the information provided in the French Nutrition and Health Program (Programme National Nutrition Santé) guidelines $^{(31)}$, leading to nine AF groups (fish, red meat, processed meat, poultry, eggs, milk, cheese, yoghurt, cream desserts). A single composite dish could be classified into several different groups. A ratio of animal added fats to total added fats was also used to assess the proportion of animal added fats in dietary intake. We added intake of butter and other added animal fats, such as thick and single cream, lard and duck fats, and we divided by the intake of total added fats, that also includes oil, margarine and salad dressing.

\section{Statistical analysis}

The present cross-sectional analysis focused on 92036 participants included in the NutriNet-Santé Study, included between May 2009 and October 2013, living in the French metropolitan area, who had completed at least three $24 \mathrm{~h}$ dietary records at baseline, were not energy under-reporters and who had no missing data for socio-economic indicators, age or BMI (Fig. 1). Complete case analysis was therefore conducted.

For each participant, the daily average quantity of each AF group (in grams) was calculated from $24 \mathrm{~h}$ records, including weighting according to the day (weekdays or weekend) to take into account the effect of whether the dietary record was done on a weekend or a weekday. Energy under-reporting participants were identified by the method of Black ${ }^{(32)}$. Briefly, BMR was estimated by the Schofield equations ${ }^{(33)}$ according to sex, age, weight and height collected at enrolment in the study. The ratio of energy intake to BMR was compared with a physical activity level of 1.55 or below, the WHO value for 'light' activity, so as to identify energy under-reporting participants ${ }^{(32)}$. The latter were consequently excluded from analysis. In addition, participants had the option of indicating whether the reported consumption was representative of his/her usual diet or differed considerably (due to illness, dieting, a social event, etc.); this information was taken into account to identify specific conditions that might objectively explain low energy intake. Energy under-reporting during a $24 \mathrm{~h}$ record might not be due solely to conscious or unconscious omission of food items, but also to under-eating that day because of specific conditions that might objectively explain low energy intake ${ }^{(32)}$. When participants declared that reported consumption was not representative of his/her usual diet (mainly due to illness in our sample), they were not considered as under-reporters ${ }^{(34)}$. The $24 \mathrm{~h}$ record was

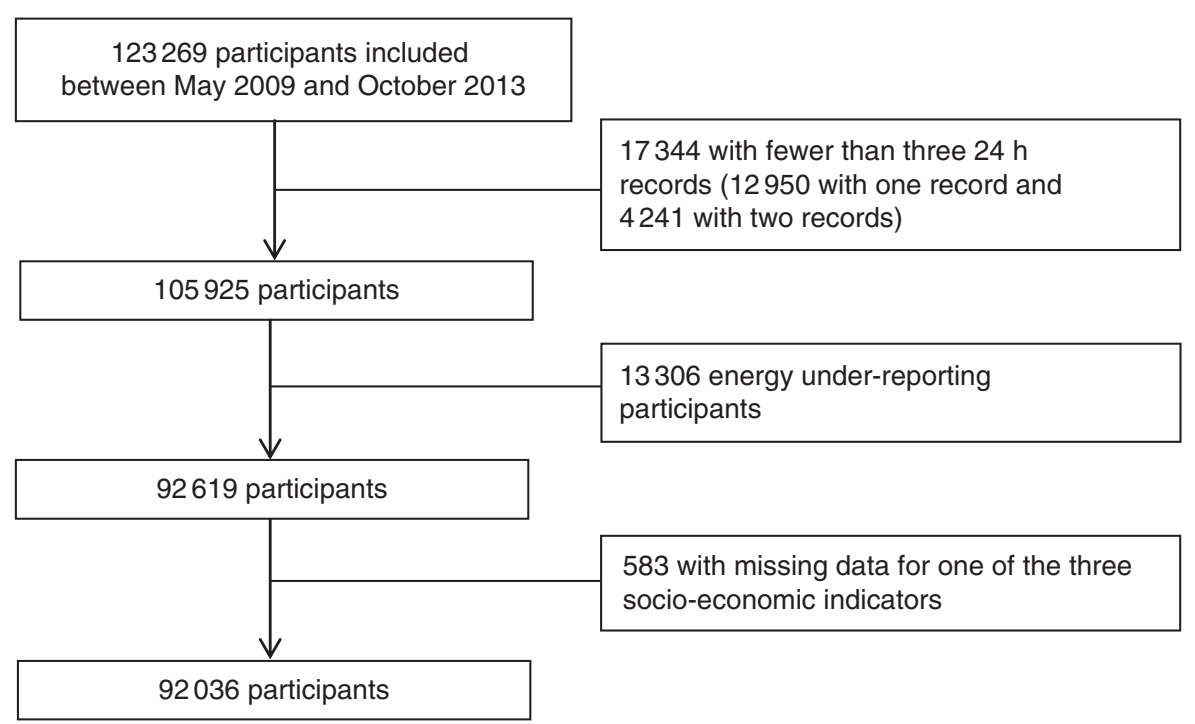

Fig. 1 Flowchart showing selection of participants for the present study 
consequently kept and the daily average energy intake was calculated from the three $24 \mathrm{~h}$ records.

Independent associations between socio-economic factors and intake of multiple $\mathrm{AF}$ were examined using ANCOVA, with the most highly educated group, the highest income group and the managerial group as references. In addition, associations between socio-economic indicators and the fact that the person was a consumer, i.e. that he/she reported eating the food at one of these three recordings at least one time (compared with those who did not report consuming the food at any of the three recordings), were assessed using logistic regression. First, models adjusted for total energy intake, age, BMI and total AF intake were constructed. Then, the three socio-economic indicators (education, income and occupation) were included together in the models. Collinearity between the three SEP indicators was investigated by examining the variance inflation factor, with a value of 4 as the maximum level to identify collinearity ${ }^{(35)}$. All analyses were performed separately for men and women, since gender interactions were found.

Linear and non-linear effects were tested. A $P$ value of $<0.05$ was initially considered statistically significant. Then, to take into account multiple comparisons, we calculated the Bonferroni correction, leading to a $P$ value of $<0.002$ (twenty tests for each type of model). Because the large sample size increased the likelihood of significant findings, a result concerning mean intake was interpreted as significant if it had a $P$ value of $<0.002$ and if the difference in mean intake between individuals in the highest SEP category and those in the lowest category was clinically relevant. Based on results of meta-analyses on the effects of $\mathrm{AF}$ intake on cancers and $\mathrm{CVD}^{(1,4,36-38)}$, the difference in intake of red meat, processed meat, poultry, fish, eggs and cheese was considered significant if it was $>5 \mathrm{~g} / \mathrm{d}$. The difference in milk intake was interpreted as significant if it was $>20 \mathrm{~g} / \mathrm{d}$, while the threshold was $12 \mathrm{~g} / \mathrm{d}$ for yoghurt and cream dessert intake. We felt that these differences in intake of $\mathrm{AF}$ between groups could have a long-term impact on the incidence of CVD and cancer. For associations between the fact that the person was a consumer and socio-economic indicators, a result was interpreted as significant with a $P$ value of $<0 \cdot 002$. Interactions between income and education or occupation, and between education and occupation, were also tested. When the interaction between income and the other two SEP indicators was significant ( $P$ value of $<0 \cdot 05)$, we performed stratified analyses of associations between $\mathrm{AF}$ intake and income by educational or occupational strata. Results for interactions between education and occupation are not shown.

Individuals unwilling to declare their income had highly diversified sociodemographic profiles, so we did not interpret comparisons between their intakes and those of the other income classes. To optimize the robustness of statistical tests, we performed sensitivity analyses by reanalysing data after exclusion of participants unwilling to declare income. For occupational categories, comparisons between intakes of self-employed and never-employed participants and those of the other occupational categories were not interpreted, since these two groups are strongly heterogeneous in terms of social status and networks. However, we hypothesized that they were part of a socio-economic gradient in terms of AF intake, along with the other occupational classes. They were therefore included in multivariate analysis. Since the category 'never-employed participants' was heterogeneous in terms of social status and networks, and was composed of students ( $n$ 4372), homemakers and disabled persons ( $n$ 656), sensitivity analyses were performed by excluding homemakers and disabled persons, using an approach identical to that described above. Data management and statistical analyses were performed using the statistical software package SAS version 9.3 .

\section{Results}

Comparisons between participants in the analysis sample and those who provided one or two $24 \mathrm{~h}$ records showed that the percentage of young persons (18-30 years), employees/manual workers (for men) and persons unwilling to divulge their income was lower in the final sample used for analyses than for those with one or two records (data not shown). Percentages of young persons, those with an undergraduate educational level, employees, never employed and those in the lowest income class were higher for women than for men (Table 1).

Table 1 Characteristics of the sample of adults ( $n$ 92036) participating in the NutriNet-Santé Study, France, May 2009October 2013

\begin{tabular}{|c|c|c|c|c|c|}
\hline & \multicolumn{2}{|c|}{$\begin{array}{l}\text { Women } \\
(n \text { 72 252) }\end{array}$} & \multicolumn{2}{|c|}{$\begin{array}{c}\text { Men } \\
(n 19784)\end{array}$} & \multirow[b]{2}{*}{$P$ value } \\
\hline & $n$ & $\%$ & $n$ & $\%$ & \\
\hline Age & & & & & $<0.0001$ \\
\hline $18-30$ years & 18460 & 25.5 & 2930 & $14 \cdot 8$ & \\
\hline $30-50$ years & 30369 & $42 \cdot 0$ & 7200 & $36 \cdot 4$ & \\
\hline $50-65$ years & 20034 & $27 \cdot 7$ & 6922 & 34.9 & \\
\hline$>65$ years & 3389 & 4.7 & 2732 & $13 \cdot 8$ & \\
\hline Educational level & & & & & $<0.0001$ \\
\hline Primary & 1905 & $2 \cdot 6$ & 689 & 3.5 & \\
\hline Secondary & 24199 & 33.5 & 6686 & 33.8 & \\
\hline Undergraduate & 23418 & $32 \cdot 4$ & 4830 & 24.4 & \\
\hline Postgraduate & 22730 & 31.4 & 7579 & $38 \cdot 3$ & \\
\hline Occupational category & & & & & $<0.0001$ \\
\hline Self-employed & 2041 & $2 \cdot 8$ & 953 & $4 \cdot 8$ & \\
\hline Never employed & 4400 & $6 \cdot 1$ & 628 & $3 \cdot 2$ & \\
\hline Manual worker & 1448 & $2 \cdot 0$ & 1027 & $5 \cdot 2$ & \\
\hline Employee & 24600 & $34 \cdot 0$ & 2722 & $13 \cdot 8$ & \\
\hline Intermediate profession & 19481 & $26 \cdot 9$ & 4642 & 23.5 & \\
\hline Managerial staff & 20282 & $28 \cdot 1$ & 9812 & $49 \cdot 6$ & \\
\hline $\begin{array}{l}\text { Monthly household } \\
\text { income group }\end{array}$ & & & & & $<0.0001$ \\
\hline Unwilling to declare & 9334 & $12 \cdot 9$ & 1364 & 6.9 & \\
\hline$<1200 €$ & 13317 & $18 \cdot 4$ & 2477 & $12 \cdot 5$ & \\
\hline $1200-1800 €$ & 18142 & $25 \cdot 1$ & 4556 & 23.0 & \\
\hline $1800-2700 €$ & 16299 & $22 \cdot 6$ & 5072 & $25 \cdot 6$ & \\
\hline$>2700 €$ & 15160 & $20 \cdot 9$ & 6315 & 31.9 & \\
\hline
\end{tabular}


Percentages of the elderly ( $>65$ years), those with a postgraduate education, managerial staff, manual workers, self-employed and those in the highest income class were lower for women than for men. Overall, the variance inflation factor of each SEP indicator was between 1.22 and 1.49, indicating that SEP indicators were not collinear. Only results on associations between binary variables and socio-economic indicators with a $P$ value of $<0.002$, and between quantitative variables and socio-economic indicators considered to be clinically relevant, are described. No difference from the main results was found in sensitivity analysis when individuals unwilling to declare their income or homemakers and disabled persons were excluded (data not shown).

\section{Associations between education and animal foods intake}

For both genders, intake of red meat (difference: +9 to $12 \mathrm{~g} / \mathrm{d}$ ), processed meat (difference: +6 to $9 \mathrm{~g} / \mathrm{d}$ ) and poultry (difference: $+7 \mathrm{~g} / \mathrm{d}$ in men) was significantly higher in persons from the lowest education level compared with those from the highest (Tables 2 and 3). Individuals from the two intermediate education levels (secondary education and undergraduate) had intermediate $\mathrm{AF}$ intake for all food groups between the highest and the lowest levels, highlighting an educational gradient in AF intake (data not tabulated). Although no difference was found in mean intake of yoghurts and cream desserts (only in women), the percentage of yoghurt consumers was lower in persons with the lowest education level compared with those with the highest, while the percentage of consumers of cream desserts was higher (see online supplementary material, Supplemental Table 1). Differences between high and low educational categories for AF intake in models not adjusted for occupation and income were higher than in models adjusted for the two indicators, particularly for intake of poultry and milk (Supplemental Table 2 and Supplemental Table 3).

\section{Associations between income and animal foods intake}

Although no difference was observed in mean fish intake, the percentage of consumers of this food group was lower

Table 2 Differences in animal food group intakes between the highest and lowest SEP categories of occupation, household income and education in women ( $n$ 72252) participating in the NutriNet-Santé Study, France, May 2009-October 2013; results from fully adjusted models*

\begin{tabular}{|c|c|c|c|c|c|c|c|c|}
\hline \multirow[b]{2}{*}{ Animal food group } & \multicolumn{2}{|c|}{$\begin{array}{l}\text { Intake }(\mathrm{g} / \mathrm{d}) \text { in } \\
\text { total sample }\end{array}$} & \multicolumn{2}{|l|}{ Occupation } & \multicolumn{2}{|c|}{$\begin{array}{l}\text { Monthly household } \\
\text { income }\end{array}$} & \multicolumn{2}{|l|}{ Education } \\
\hline & Mean & SD & $\begin{array}{l}\text { Difference between } \\
\text { managerial staff and } \\
\text { manual workers } \\
(\mathrm{g} / \mathrm{d} \text { or } \%) \dagger\end{array}$ & $P$ value $\ddagger$ & $\begin{array}{c}\text { Difference } \\
\text { between } \\
>2700 € \text { and } \\
<1200 € \\
(\mathrm{~g} / \mathrm{d} \text { or } \%) \dagger\end{array}$ & $P$ value & $\begin{array}{c}\text { Difference } \\
\text { between } \\
\text { postgraduate and } \\
\text { primary level } \\
(\mathrm{g} / \mathrm{d} \text { or } \%) \dagger\end{array}$ & $P$ value $\neq$ \\
\hline \multicolumn{9}{|l|}{ Fish } \\
\hline $\begin{array}{l}\text { Mean intake in consumers } \\
\text { Red meat }\end{array}$ & $47 \cdot 1$ & $37 \cdot 7$ & $4 \cdot 2$ & $<0.0001$ & 3.0 & 0.002 & $-2 \cdot 2$ & 0.12 \\
\hline $\begin{array}{l}\text { Mean intake in consumers } \\
\text { Processed meat }\end{array}$ & $56 \cdot 3$ & $38 \cdot 4$ & -0.3 & $<0.0001$ & -0.8 & 0.49 & $-8 \cdot 6$ & $<0.0001$ \\
\hline $\begin{array}{l}\text { Mean intake in consumers } \\
\text { Poultry }\end{array}$ & $37 \cdot 1$ & $29 \cdot 4$ & $-1 \cdot 3$ & 0.001 & $-0 \cdot 1$ & 0.67 & $-6 \cdot 0$ & $<0.0001$ \\
\hline $\begin{array}{l}\text { Mean intake in consumers } \\
\text { Eggs }\end{array}$ & $40 \cdot 7$ & $32 \cdot 3$ & $-3 \cdot 7$ & 0.007 & 0.6 & 0.79 & $-4 \cdot 7$ & 0.0008 \\
\hline $\begin{array}{l}\text { Mean intake in consumers } \\
\text { Milk }\end{array}$ & $23 \cdot 0$ & $22 \cdot 7$ & -0.4 & $<0.0001$ & $2 \cdot 9$ & 0.04 & $-1 \cdot 8$ & 0.002 \\
\hline $\begin{array}{l}\text { Mean intake in consumers } \\
\text { Cheese }\end{array}$ & $143 \cdot 3$ & $136 \cdot 4$ & $-19 \cdot 1$ & $<0.0001$ & $-17 \cdot 4$ & $<0.0001$ & $-9 \cdot 9$ & $<0.0001$ \\
\hline $\begin{array}{l}\text { Mean intake in the whole } \\
\text { sample }\end{array}$ & $35 \cdot 2$ & $28 \cdot 3$ & $1 \cdot 3$ & 0.11 & -0.6 & 0.89 & $2 \cdot 3$ & $<0.0001$ \\
\hline Yoghurt & & & & & & & & \\
\hline $\begin{array}{l}\text { Mean intake in consumers } \\
\text { Cream desserts }\end{array}$ & $120 \cdot 8$ & $106 \cdot 4$ & $7 \cdot 1$ & 0.19 & $10 \cdot 3$ & 0.005 & $-4 \cdot 7$ & 0.05 \\
\hline $\begin{array}{l}\text { Mean intake in consumers } \\
\text { Added animal fats }\end{array}$ & $75 \cdot 7$ & 53.7 & $-2 \cdot 4$ & 0.004 & $-5 \cdot 2$ & 0.52 & $-8 \cdot 4$ & $<0.0001$ \\
\hline $\begin{array}{l}\text { Ratio of added animal fats to } \\
\text { total added fats§ }\end{array}$ & 0.33 & 0.26 & -0.02 & 0.0007 & 0.0 & 0.28 & 0.0 & 0.77 \\
\hline
\end{tabular}

SEP, socio-economic position.

${ }^{\star}$ All models were adjusted for age, total energy intake, BMI, total animal foods intake, occupation, household income and education. In bold, result interpreted as significant; i.e. with a $P$ value of $<0.002$, and when the difference in mean intake between individuals belonging to the highest SEP category and those of the lowest category was clinically significant, i.e. $>5 \mathrm{~g} / \mathrm{d}$ for intake of fish, red meat, processed meat, poultry, eggs and cheese, $>20 \mathrm{~g} / \mathrm{d}$ for milk intake and $>12 \mathrm{~g} / \mathrm{d}$ for yoghurt intake.

†Subtraction of mean intake $(\mathrm{g} / \mathrm{d})$ or percentage of consumers between individuals belonging to the highest socio-economic category and those in the lowest category.

$\ddagger P$ value for non-linear association.

§Ratio of intake of animal added fats to intake of total added fats, in the whole sample. 
in the lowest income category than in the highest category (see online supplementary material, Supplemental Table 1). Differences between high and low income classes in intake of red meat (in men), poultry (in men) and cream desserts (in men) in models not adjusted for occupation and education were significant compared with fully adjusted models (Supplemental Table 2 and Supplemental Table 3).

\section{Associations between occupation and animal foods intake}

In men, higher intake of cream desserts was reported for manual workers compared with managerial staff (difference: $+14 \mathrm{~g} / \mathrm{d}$; Table 3). Employees had higher intake of cream desserts than manual workers and lower intake than managerial staff; there was no difference between intermediate professions and managerial staff (data not tabulated). Although no difference was found for mean intake of yoghurts and cream desserts (only in women), the percentage of yoghurt consumers was lower in manual workers than in managerial staff, while the percentage of cream dessert consumers was higher (see online supplementary material, Supplemental Table 1). In fully adjusted models, differences according to occupational categories were non-significant or lower for many AF groups, such as red meat, poultry, milk and cream desserts (in women), compared with models not adjusted for the other two indicators (Supplemental Table 2 and Supplemental Table 3).

\section{Stratified analyses}

Significant interactions were found for yoghurt intake between education and income (women, $P=0.004$; men, $P=0.02$ ) and between occupation and income, but only in women $(P=0.009)$. For both genders, stratified results by education level showed, in individuals with primary education only, that those belonging to the highest income class consumed higher quantities of yoghurt than persons in the lower categories (Tables 4 and 5). For stratified results in women by occupational group, no difference in yoghurt intake according to income class was interpreted as significant whatever the occupational category (Table 6). In men, there was a significant interaction between education and income for red meat $(P=0 \cdot 02)$. In stratified analysis by educational level, no significant

Table 3 Differences in animal food group intakes between the highest and lowest SEP categories of occupation, household income and education in men ( $n$ 19784) participating in the NutriNet-Santé Study, France, May 2009-October 2013; results from fully adjusted models*

\begin{tabular}{|c|c|c|c|c|c|c|c|c|}
\hline \multirow[b]{2}{*}{ Food groups } & \multicolumn{2}{|c|}{$\begin{array}{l}\text { Intake }(g / d) \text { in } \\
\text { total sample }\end{array}$} & \multicolumn{2}{|l|}{ Occupation } & \multicolumn{2}{|c|}{ Monthly household income } & \multicolumn{2}{|c|}{ Education } \\
\hline & Mean & SD & $\begin{array}{l}\text { Difference between } \\
\text { managerial staff } \\
\text { and manual workers } \\
(\mathrm{g} / \mathrm{d} \text { or } \%) \dagger\end{array}$ & $P$ value $\ddagger$ & $\begin{array}{c}\text { Difference } \\
\text { between }>2700 € \\
\text { and }<1200 € \\
(\mathrm{~g} / \mathrm{d} \text { or } \%) \dagger\end{array}$ & $\begin{array}{c}P \\
\text { value } \neq\end{array}$ & $\begin{array}{l}\text { Difference } \\
\text { between } \\
\text { postgraduate } \\
\text { and primary } \\
\text { level }(\mathrm{g} / \mathrm{d} \%) \dagger\end{array}$ & $P$ value \\
\hline \multicolumn{9}{|l|}{ Fish } \\
\hline $\begin{array}{l}\text { Mean intake in consumers } \\
\text { Red meat }\end{array}$ & $55 \cdot 0$ & $44 \cdot 6$ & $-1 \cdot 8$ & 0.57 & 3.7 & 0.02 & $-3 \cdot 2$ & 0.06 \\
\hline $\begin{array}{l}\text { Mean intake in consumers } \\
\text { Processed meat }\end{array}$ & $74 \cdot 2$ & $50 \cdot 2$ & $-2 \cdot 3$ & 0.87 & $-1 \cdot 5$ & 0.02 & $-9 \cdot 7$ & $<0.0001$ \\
\hline $\begin{array}{l}\text { Mean intake in consumers } \\
\text { Poultry }\end{array}$ & $48 \cdot 8$ & $39 \cdot 7$ & $-2 \cdot 8$ & 0.41 & $-3 \cdot 4$ & 0.005 & $-8 \cdot 0$ & 0.0008 \\
\hline $\begin{array}{l}\text { Mean intake in consumers } \\
\text { Eggs }\end{array}$ & $48 \cdot 7$ & $39 \cdot 4$ & $-3 \cdot 7$ & 0.01 & $-1 \cdot 1$ & 0.43 & $-6 \cdot 4$ & 0.001 \\
\hline $\begin{array}{l}\text { Mean intake in consumers } \\
\text { Milk }\end{array}$ & $26 \cdot 0$ & $27 \cdot 1$ & -3.6 & 0.02 & $-3 \cdot 2$ & 0.29 & $-2 \cdot 2$ & 0.18 \\
\hline $\begin{array}{l}\text { Mean intake in consumers } \\
\text { Cheeses }\end{array}$ & $160 \cdot 3$ & $149 \cdot 5$ & $-18 \cdot 0$ & 0.0007 & $-3 \cdot 7$ & 0.38 & $-2 \cdot 9$ & 0.06 \\
\hline $\begin{array}{l}\text { Mean intake in the whole } \\
\text { sample } \\
\text { Yoghurt }\end{array}$ & $46 \cdot 1$ & $35 \cdot 9$ & $4 \cdot 3$ & 0.02 & -0.1 & 0.59 & $2 \cdot 5$ & 0.31 \\
\hline $\begin{array}{l}\text { Mean intake in consumers } \\
\text { Cream desserts }\end{array}$ & $115 \cdot 8$ & $85 \cdot 9$ & -11.4 & 0.004 & $5 \cdot 4$ & $0 \cdot 14$ & $-3 \cdot 1$ & 0.14 \\
\hline $\begin{array}{l}\text { Mean intake in consumers } \\
\text { Added animal fats }\end{array}$ & $85 \cdot 3$ & $64 \cdot 9$ & $-12 \cdot 2$ & $<0.0001$ & $-5 \cdot 1$ & 0.75 & -0.7 & 0.56 \\
\hline $\begin{array}{l}\text { Ratio of added animal fats to } \\
\text { total added fats } \S\end{array}$ & 0.30 & 0.26 & 0.01 & 0.35 & 0 & 0.54 & 0 & 0.25 \\
\hline
\end{tabular}

SEP, socio-economic position.

${ }^{*}$ All models were adjusted for age, total energy intake, BMI, total animal foods intake, occupation, household income and education. In bold, result interpreted as significant; i.e. with a $P$ value of $<0.002$, and when the difference in mean intake between individuals belonging to the highest SEP category and those in the lowest category was clinically significant, i.e. $>5 \mathrm{~g} / \mathrm{d}$ for intake of fish, red meat, processed meat, poultry, eggs and cheese, $>20 \mathrm{~g} / \mathrm{d}$ for milk intake and $>12 \mathrm{~g} / \mathrm{d}$ for yoghurt intake. †Subtraction of the mean intake $(\mathrm{g} / \mathrm{d})$ or the percentage of consumers between individuals belonging to the highest socio-economic category and those in the lowest category.

$\ddagger P$ value for non-linear association

§Ratio of intake of animal added fats to intake of total added fats, in the whole sample. 
Table 4 Intake of red meat and yoghurt according to income class, stratified by education level, in men $(n$ 19784) participating in the NutriNet-Santé Study, France, May 2009-October $2013^{\star}, \dagger$

\begin{tabular}{|c|c|c|c|c|c|c|c|c|}
\hline \multirow[b]{2}{*}{ Education } & \multicolumn{4}{|c|}{ Red meat } & \multicolumn{4}{|c|}{ Yoghurt } \\
\hline & Mean $(g / d)$ & SE & $\begin{array}{c}\text { Difference between } \\
>2700 € \text { and }<1200 € \\
(\mathrm{~g} / \mathrm{d}) \ddagger\end{array}$ & $P$ value & $\begin{array}{c}\text { Mean } \\
(\mathrm{g} / \mathrm{d})\end{array}$ & SE & $\begin{array}{c}\text { Difference between } \\
>2700 € \text { and }<1200 € \\
(\mathrm{~g} / \mathrm{d}) \ddagger\end{array}$ & $P$ value \\
\hline \multicolumn{9}{|c|}{ Participants with primary education level } \\
\hline$<1200 € /$ month & $91 \cdot 8$ & 8.8 & 4.6 & 0.06 & $107 \cdot 2$ & 13.9 & 21.5 & 0.0001 \\
\hline $1200-1800 € /$ month & $87 \cdot 4$ & 8.9 & 4.8 & & $99 \cdot 3$ & $12 \cdot 1$ & $29 \cdot 3$ & \\
\hline $1800-2700 € /$ month & $82 \cdot 8$ & 7.5 & 9.2 & & $110 \cdot 9$ & $12 \cdot 8$ & $18 \cdot 8$ & \\
\hline$>2700 € /$ month & $87 \cdot 6$ & 8.3 & & & 129.4 & 13.8 & & \\
\hline \multicolumn{9}{|c|}{ Participants with secondary education level } \\
\hline \multicolumn{9}{|c|}{ Income classes } \\
\hline$<1200 € /$ month & $75 \cdot 7$ & $1 \cdot 7$ & 0.9 & 0.40 & $115 \cdot 3$ & 3.5 & $4 \cdot 2$ & 0.07 \\
\hline $1200-1800 € /$ month & $79 \cdot 2$ & 1.4 & $-2 \cdot 6$ & & $119 \cdot 4$ & $2 \cdot 8$ & 9.4 & \\
\hline $1800-2700 € /$ month & 75.4 & 1.5 & 1.2 & & $116 \cdot 6$ & 3.0 & $12 \cdot 7$ & \\
\hline$>2700 € /$ month & 76.5 & 1.9 & & & $119 \cdot 6$ & 3.6 & & \\
\hline \multicolumn{9}{|c|}{ Participants with undergraduate education level } \\
\hline \multicolumn{9}{|c|}{ Income classes } \\
\hline$<1200 € /$ month & 73.6 & $2 \cdot 4$ & -0.5 & 0.34 & $116 \cdot 2$ & 4.9 & $-5 \cdot 1$ & 0.49 \\
\hline $1200-1800 € /$ month & $70 \cdot 2$ & $2 \cdot 0$ & $2 \cdot 8$ & & $109 \cdot 1$ & 4.0 & 1.7 & \\
\hline $1800-2700 € /$ month & 73.9 & $2 \cdot 1$ & -0.8 & & $116 \cdot 4$ & $4 \cdot 1$ & $-5 \cdot 3$ & \\
\hline$>2700 € /$ month & 73.1 & $2 \cdot 2$ & & & 111.2 & 4.3 & & \\
\hline \multirow{2}{*}{\multicolumn{9}{|c|}{ Participants with postgraduate education level }} \\
\hline & & & & & & & & \\
\hline$<1200 € /$ month & 76.5 & 3.0 & $-5 \cdot 3$ & 0.26 & $106 \cdot 3$ & $5 \cdot 8$ & 4.0 & 0.28 \\
\hline $1200-1800 € /$ month & 72.9 & 2.5 & -1.7 & & 106.5 & 4.9 & 3.3 & \\
\hline $1800-2700 € /$ month & $71 \cdot 1$ & $2 \cdot 4$ & 0.1 & & $107 \cdot 8$ & $4 \cdot 6$ & 3.2 & \\
\hline$>2700 € /$ month & $71 \cdot 2$ & $2 \cdot 3$ & & & $110 \cdot 2$ & 4.4 & & \\
\hline
\end{tabular}

SEP, socio-economic position.

${ }^{*}$ All models for food group intake were adjusted for age, total energy intake, BMI, total animal foods intake and occupation. In bold, result interpreted as significant, i.e. with a $P$ value of $<0.002$, and when the difference in mean intake between individuals belonging to the highest SEP category and those in the lowest category was clinically significant, i.e. $>5 \mathrm{~g} / \mathrm{d}$ for intake of red meat and $>12 \mathrm{~g} / \mathrm{d}$ for yoghurt intake.

†Mean intake in consumers only.

¥Subtraction of the mean intake $(\mathrm{g} / \mathrm{d})$ between individuals belonging to the highest socio-economic category and those in the lowest category.

difference in red meat intake was found according to income class whatever the educational level (Table 4). In women, a significant interaction between education and income was observed for milk consumers $(P=0 \cdot 0001)$. In stratified analysis by educational level, no significant difference in milk intake was found according to income class whatever the education level (Table 5). In women, interactions between education and income for intake and percentage of cream dessert consumers were significant (respectively $P=0.02$ and $P=0.06$ ). Stratified results showed a very slight difference in cream dessert intake (difference: -2 to $6 \mathrm{~g} / \mathrm{d}$ ) and the percentage of consumers (difference: $+2 \%$ ) according to income group in secondary and undergraduate educational strata, while no significant difference was found in primary or postgraduate levels (data not tabulated).

\section{Discussion}

Compared with persons of high socio-economic status, consumers of red and processed meats and cream desserts were more numerous at lower socio-economic levels, and the latter also had higher mean intakes of these foods.
In contrast, the percentage of consumers of fish and yoghurt among persons with low socio-economic status was lower than in those of high socio-economic status. The relationship between AF intake and SEP varied according to the socio-economic indicator used and these indicators rarely interacted.

Our study confirms that each SEP indicator was independently associated with at least one dietary outcome. In agreement with the literature ${ }^{(11,39-40)}$, a lower education level was associated with higher intake of unhealthy $\mathrm{AF}$, particularly meat products, and education level modulated relationships between income and intake of dairy products. Occupation and income were associated with percentage of consumers of dairy products. Differences between high and low educational categories in $\mathrm{AF}$ intake in models not adjusted for occupation or income were slightly higher than in models adjusted for the other two indicators. In contrast, in fully adjusted models, these differences according to occupational category and, to a lesser extent, according to income class were substantially attenuated for many AF groups compared with unadjusted models. Education therefore appears to be the strongest and most robust independent predictor of $\mathrm{AF}$ intake. It determines the occupation and income $^{(16,17)}$, and may influence the understanding and 
Table 5 Intake of yoghurt and percentage of milk consumers according to income category, stratified by education level, in women ( $n$ 72 252) participating in the NutriNet-Santé Study, France, May 2009-October 2013*

\begin{tabular}{|c|c|c|c|c|c|c|c|}
\hline \multirow[b]{2}{*}{ Education } & \multicolumn{4}{|c|}{ Yoghurt } & \multicolumn{3}{|c|}{ Milk } \\
\hline & Mean $(g / d) \dagger$ & SE & $\begin{array}{l}\text { Difference between } \\
>2700 € \text { and } \\
<1200 €(\mathrm{~g} / \mathrm{d}) \ddagger\end{array}$ & $P$ value & $\begin{array}{l}\text { Milk } \\
\text { consumers } \\
(\%)\end{array}$ & $\begin{array}{l}\text { Difference between } \\
>2700 € \text { and } \\
<1200 €(\%) \ddagger\end{array}$ & $P$ value \\
\hline \multicolumn{8}{|c|}{ Participants with primary education level } \\
\hline \multicolumn{8}{|c|}{ Income category } \\
\hline$<1200 € /$ month & $13 \cdot 0$ & $6 \cdot 0$ & $32 \cdot 1$ & 0.0001 & $56 \cdot 4$ & $-9 \cdot 7$ & 0.0001 \\
\hline $1200-1800 € /$ month & 113.7 & $5 \cdot 7$ & $31 \cdot 3$ & & 61.7 & $-15 \cdot 1$ & \\
\hline $1800-2700 € /$ month & 114.8 & $7 \cdot 0$ & $30 \cdot 2$ & & $55 \cdot 9$ & $-9 \cdot 2$ & \\
\hline$>2700 € /$ month & $145 \cdot 1$ & $9 \cdot 6$ & & & $46 \cdot 7$ & & \\
\hline \multicolumn{8}{|c|}{ Participants with secondary education level } \\
\hline \multicolumn{8}{|c|}{ Income classes } \\
\hline$<1200 € /$ month & $117 \cdot 2$ & $1 \cdot 7$ & 3.7 & 0.02 & $58 \cdot 1$ & $-3 \cdot 2$ & $<0.0001$ \\
\hline $1200-1800 € /$ month & 120.5 & 1.6 & 0.4 & & $61 \cdot 2$ & $-6 \cdot 4$ & \\
\hline $1800-2700 € /$ month & 124.7 & 1.8 & -3.8 & & $55 \cdot 0$ & $-0 \cdot 1$ & \\
\hline$>2700 € /$ month & $120 \cdot 9$ & $2 \cdot 2$ & & & $54 \cdot 8$ & & \\
\hline \multicolumn{8}{|c|}{ Participants with undergraduate education level } \\
\hline \multicolumn{8}{|c|}{ Income classes } \\
\hline$<1200 € /$ month & 114.9 & $2 \cdot 4$ & 1.9 & 0.002 & $56 \cdot 1$ & $-1 \cdot 8$ & 0.009 \\
\hline $1200-1800 € /$ month & $121 \cdot 1$ & $2 \cdot 2$ & $-4 \cdot 4$ & & $58 \cdot 0$ & -3.8 & \\
\hline $1800-2700 € /$ month & 121.9 & $2 \cdot 3$ & $-5 \cdot 2$ & & $57 \cdot 3$ & -3.0 & \\
\hline$>2700 € /$ month & 116.7 & $2 \cdot 4$ & & & $54 \cdot 3$ & & \\
\hline \multicolumn{8}{|c|}{ Participants with postgraduate education level } \\
\hline \multicolumn{8}{|c|}{ Income classes } \\
\hline$<1200 € /$ month & $116 \cdot 3$ & 3.3 & 6.4 & $0.02 \S$ & $57 \cdot 7$ & -0.6 & 0.38 \\
\hline $1200-1800 € /$ month & 118.3 & 3.1 & $4 \cdot 3$ & & $55 \cdot 0$ & $2 \cdot 1$ & \\
\hline $1800-2700 € /$ month & 118.9 & 3.0 & 3.7 & & 56.5 & 0.6 & \\
\hline$>2700 € /$ month & $122 \cdot 6$ & 2.9 & & & $57 \cdot 1$ & & \\
\hline
\end{tabular}

SEP, socio-economic position.

*All models for food group intake and percentage of consumers were adjusted for age, total energy intake, BMI, total animal foods intake and occupation. In bold, result interpreted as significant; i.e. with a $P$ value of $<0.002$, and when the difference in mean intake between individuals belonging to the highest SEP category and those in the lowest category was clinically significant, i.e. $>12 \mathrm{~g} / \mathrm{d}$ for yoghurt intake.

†Mean intake in consumers only.

$\ddagger$ Subtraction of the mean intake $(\mathrm{g} / \mathrm{d})$ or the percentage of consumers between individuals belonging to the highest socio-economic category and those in the lowest category.

$\S P$ value for linear association.

importance accorded to preventive health measures and the capacity to generate behaviour that is beneficial on a longterm basis, such as low intake of meat ${ }^{(13,16)}$. Occupation may influence intake partly via workplace behaviour and the social environment, while income has a direct impact on diet through financial resources ${ }^{(13)}$. Differences between unadjusted and fully adjusted models also suggest that use of a single SEP measure might lead to misinterpreting relationships between the SEP indicator and dietary intake, and confirm that they should be studied simultaneously ${ }^{(13,14)}$. Under- or overestimation of socio-economic disparities in $\mathrm{AF}$ intake may have implications for public health strategies. Our findings provide information useful for identifying subgroups of the population at high nutritional risk in terms of AF intake. This is a key element when implementing nutritional public health measures targeting disadvantaged groups, particularly in the current context of health inequalities, which remain important.

\section{Red meat, processed meat, poultry and fish}

Results concerning red and processed meat were in agreement with the literature ${ }^{(11,40-42)}$. In particular, our study highlighted the importance of education compared with other socio-economic factors. Less-well-educated persons may not clearly perceive the negative health implications of consuming red and processed meat. In addition, the symbolic role of meat (i.e. its supposed contribution to physical strength and energy), along with existing social norms in this population, may affect the decision to continue eating meat despite its cost ${ }^{(43)}$. Understanding why persons with less education prefer eating meat is critical, since they are more strongly affected by chronic diseases for which meat intake is a risk factor ${ }^{(1,9,10)}$.

Our results regarding poultry agreed with a French study showing an inverse association between education and intake of white meat ${ }^{(21)}$, but was not consistent with most previous studies ${ }^{(11)}$. More highly educated individuals were possibly more concerned by food safety crises in the meat industry over the last decade; consequently, they may have reduced their overall intake of meat-based foods, including poultry. Moreover, a vegetarian lifestyle is more frequently found in this group ${ }^{(44)}$.

Our finding regarding the relationship between income and fish consumption was in agreement with the few available studies that used income as a socio-economic indicator $^{(42,45,46)}$. The lower percentage of fish consumers 
Table 6 Intake of yoghurt according to income group, stratified by occupational category, in women ( $n$ 72252) participating in the NutriNet-Santé Study, France, May 2009-October 2013*

\begin{tabular}{|c|c|c|c|c|}
\hline \multirow[b]{2}{*}{ Occupation } & \multicolumn{4}{|c|}{ Yoghurt } \\
\hline & Mean $(\mathrm{g} / \mathrm{d}) \dagger$ & SE & $\begin{array}{c}\text { Difference } \\
\text { between }>2700 € \\
\text { and }<1200 €(\mathrm{~g} / \mathrm{d}) \ddagger\end{array}$ & $P$ value \\
\hline \multicolumn{5}{|l|}{ Manual workers } \\
\hline \multicolumn{5}{|l|}{ Income classes } \\
\hline$<1200 € /$ month & 113.6 & $7 \cdot 1$ & -4.9 & 0.15 \\
\hline $1200-1800 € /$ month & $126 \cdot 9$ & 7.4 & $-18 \cdot 3$ & \\
\hline $1800-2700 € /$ month & $107 \cdot 3$ & 10.5 & 1.4 & \\
\hline$>2700 € /$ month & $108 \cdot 7$ & 18.8 & & \\
\hline \multicolumn{5}{|l|}{ Employees } \\
\hline \multicolumn{5}{|l|}{ Income classes } \\
\hline$<1200 € /$ month & $118 \cdot 2$ & 1.8 & 1.4 & 0.02 \\
\hline $1200-1800 € /$ month & 120.7 & 1.5 & $-1 \cdot 1$ & \\
\hline $1800-2700 € /$ month & $126 \cdot 0$ & 1.8 & $-6 \cdot 4$ & \\
\hline$>2700 € /$ month & 119.6 & 2.6 & & \\
\hline \multicolumn{5}{|l|}{ Intermediate professions } \\
\hline \multicolumn{5}{|l|}{ Income classes } \\
\hline$<1200 € /$ month & $116 \cdot 5$ & $2 \cdot 9$ & 2.5 & 0.16 \\
\hline $1200-1800 € /$ month & 121.4 & $2 \cdot 3$ & -2.5 & \\
\hline $1800-2700 € /$ month & $122 \cdot 2$ & $2 \cdot 2$ & $-3 \cdot 2$ & \\
\hline$>2700 € /$ month & $119 \cdot 0$ & $2 \cdot 4$ & & \\
\hline \multicolumn{5}{|l|}{ Managerial staff } \\
\hline \multicolumn{5}{|l|}{ Income classes } \\
\hline$<1200 € /$ month & 110.5 & $4 \cdot 3$ & $10 \cdot 1$ & $0.006 \S$ \\
\hline $1200-1800 € /$ month & $117 \cdot 7$ & 3.2 & 2.9 & \\
\hline $1800-2700 € /$ month & 118.0 & 2.9 & $2 \cdot 6$ & \\
\hline$>2700 \mathrm{€} / \mathrm{month}$ & $120 \cdot 6$ & $2 \cdot 9$ & & \\
\hline
\end{tabular}

SEP, socio-economic position.

${ }^{\star}$ All models for food group intake and percentage of consumers were adjusted for age, total energy intake, BMI, total animal foods intake and occupation. In bold, result interpreted as significant; i.e. with a $P$ value of $<0.002$, and when the difference in mean intake between individuals belonging to the highest SEP category and those in the lowest category was clinically significant, i.e. $>12 \mathrm{~g} / \mathrm{d}$ for yoghurt intake.

tMean intake in consumers only.

$\ddagger$ Subtraction of the mean intake $(\mathrm{g} / \mathrm{d})$ or the percentage of consumers between individuals belonging to the highest socio-economic category and those of the lowest category.

$\S P$ value for linear association.

in persons with a lower income compared with those with a higher income may be related to the high cost of fish. Cost constraint induced a decrease in fish intake as it ranks as one of the most expensive food groups ${ }^{(47,48)}$. Unlike previous studies ${ }^{(11,13,21,42,45,49)}$, in our work, fish intake was not associated with education or occupation. However, most previous works did not simultaneously take into account several different socio-economic indicators.

\section{Dairy products}

Our findings on the absence of a relationship between SEP indicators and cheese intake contrasted with a systematic review and meta-analysis showing a positive association between education or occupation and consumption of cheese; it also highlighted substantial heterogeneity in results across European countries (not including French data), emphasizing the importance of conducting country-specific research ${ }^{(50)}$. In addition, previous works that took several socio-economic indicators into account showed ambiguous results ${ }^{(13,19,22,39,51,52)}$. A cultureoriented hypothesis might explain our results: cheese is commonly consumed in France during lunch or as a snack by the entire population; thus, no socio-economic differences were found. Our results regarding milk intake are concordant with a systematic review and meta-analysis showing no significant association of milk consumption with education or occupation ${ }^{(50)}$.

Regarding yoghurt and cream desserts, education, occupation and household income each contributed to differences in consumption. Consistent with previous studies $^{(11,23,39,40,49,53)}$, the percentage of yoghurt consumers among manual workers and, to a lesser extent, less-well-educated persons was lower, whereas individuals with low SEP ate more cream desserts than those in higher categories. Our findings suggest that socioeconomic disparities exist in choices of healthy (yoghurt) $v$. less healthy (cream dessert) dairy products, rather than socio-economic differences in overall intake of dairy products. Taken together, our results showed no differences in total intake of dairy products whatever the SEP indicator used (results not shown). Our stratified results showed no difference in yoghurt intake between income categories whatever the education level, except for the least-well-educated group. This highlights the fact that the individual capacity to understand and make use of public health information, as expressed by the education 
level ${ }^{(14,16)}$, could override the cost barrier to intake of healthy dairy products. In addition, education may involve exposure to family eating habits acquired during childhood, thereby influencing healthier dietary behaviour in adulthood $^{(16)}$. Poor dietary habits in childhood among the less educated may persist throughout adulthood; they include the choice of high-fat dairy desserts instead of yoghurt, combined with poor current dietary choices related to restrained access to better-quality but more expensive dairy foods ${ }^{(13)}$.

\section{Added animal fats}

No socio-economic differences in the ratio of intake of added animal fats to total added fats were found. Consistent with results from other European Mediterranean countries $^{(54)}$, intake of added animal fats such as butter, cream, lard and duck fats in France may be influenced by cultural or regional variations rather than socio-economic factors ${ }^{(55)}$.

\section{Study limitations}

Interpretation of the present results should take into account several limitations. Since the sample was not random, individuals belonging to high SEP groups were more numerous and had healthier lifestyles than the general population, with higher intake of fruits and vegetables ${ }^{(56)}$. Differences in dietary intake between SEP categories are probably greater in the general population. However, findings regarding intake of dairy products, meat, seafood and eggs in a nationally representative random sample of the French population ${ }^{(56)}$ showed estimates equivalent to those in our study. In addition, over-representation of women in our sample could be explained by the fact that women are more likely to participate in voluntary-based health and epidemiological studies, whatever the field ${ }^{(57)}$. Women may also be over-represented in our sample because they have greater interest in nutrition. Although only $21.5 \%$ of our sample was male, the distribution of men in the different SEP categories was sufficient to interpret differences in intake between these categories. Moreover, the large size and demographic heterogeneity of our sample provided high statistical power for investigating stratified associations of income with $\mathrm{AF}$ intake by education and occupation category. Causal inferences regarding associations between AF consumption and socio-economic characteristics must be viewed with caution due to the cross-sectional design of the present study. Unhealthy dietary habits may lead to chronic disease and obesity, thereby influencing socio-economic status. The problem of accuracy in web-based self-reported data also arises for repeated $24 \mathrm{~h}$ dietary records, compared with interviews by trained dietitians. However, the strength of our study lies in its reliance on at least three validated dietary records randomly assigned over a 2 -week period, which appears to be reliable for estimating usual dietary intake ${ }^{(28,29)}$ and is the recommended method in wide-scale epidemiological studies ${ }^{(58)}$, as it enables a valid estimate of usual $\operatorname{diet}^{(59)}$. Another limitation was that the 'occupation' criterion cannot be reliably used for social groups outside the paid workforce ${ }^{(16)}$, including homemakers, disabled persons and students. Also, self-employed persons are difficult to classify, since this category is extremely heterogeneous and includes company managers, freelancers, shopkeepers, craftspeople and workers in informal sectors of the economy. As a result, comparison between their intakes and those of the other categories may be biased. For this reason, results for these occupational categories were not interpreted, since such groups are extremely heterogeneous in terms of social status and relationships. Also, personal income is a sensitive question and participants may be reluctant to provide such information, although this point may have been overstated ${ }^{(16)}$. Since this SEP indicator is subject to more non-responses than other SEP questions, socio-economic differences may be incorrectly estimated.

\section{Conclusion}

In conclusion, our findings reveal that low socio-economic populations, particularly in terms of education, made unhealthier $\mathrm{AF}$ intake choices than persons in higher categories; these included meat products and high-fat dairy desserts instead of fish and low-fat desserts. In addition, simultaneous use of three socio-economic indicators and the study of their interactions highlighted distinct facets of SEP that may influence AF intake, consequently providing a better understanding of mechanisms leading to social inequalities in health. Further works assessing the dynamic nature of socio-economic indicators using repeated measures throughout a lifetime would be useful, since the prospective effects of their variations upon current dietary behaviour are not yet known.

\section{Acknowledgements}

Acknowledgements: The authors thank the scientists, dietitians, technicians and assistants who helped carry out the NutriNet-Santé Study, and all of the dedicated and conscientious volunteers. They especially thank Mohand Ait-Oufella, Paul Flanzy, Yasmina Chelghoum, Véronique Gourlet, Nathalie Arnault and Laurent Bourhis. The authors also thank Voluntis (a health-care software company) and MXS (a software company specializing in dietary assessment tools) for developing the NutriNetSanté web-based interface according to their guidelines; and are grateful to Jerri Bram for English editing of the manuscript. Financial support: This research has benefited from the joint assistance of the French National Health Insurance Fund for Employees (CNAMTS), the French Directorate General of Health (DGS), the Arc 
Foundation for Cancer Research, the French National Cancer Institute (INCA), the French National Institute for Prevention and Education in Health (INPES), the French National Institute of Health and Medical Research (INSERM), the French Inter-Departmental Agency for the Fight against Drugs and Addictive Behaviors (Mildeca) and the French Social Security Scheme for Liberal Professionals (RSI) as part of the 'Primary Prevention' call for proposals issued by the IRESP and INCA in 2013. The NutriNet-Santé Study is supported by the following institutions: Ministere de la Sante (DGS), Institut de Veille Sanitaire (InVS), Institut National de la Prevention et de l'Education pour la Sante (INPES), Fondation pour la Recherche Medicale (FRM), Institut de Recherche en Santé Publique (IRESP), Institut National de la Sante et de la Recherche Medicale (INSERM), Institut National de la Recherche Agronomique (INRA), Conservatoire National des Arts et Metiers (CNAM) and Université Paris 13. The funders had no role in the design, analysis or writing of this article. Conflict of interest: None of the authors had a conflict of interest. Authorship: C.M. designed the study, supervised the statistical analysis, interpreted data and drafted the manuscript. C.L. performed data management and statistical analyses. W.S.H., B.A. and S.P. were involved in the interpretation of the data and helped to draft the manuscript. S.H. designed and coordinated the study cohort and supervised the study. K.C. was involved in the conception and design of the study, in the supervision of statistical analysis and interpretation of the data, and helped to draft the manuscript. All authors critically reviewed the paper and approved the final version submitted for publication. Ethics of buman subject participation: This study was conducted according to guidelines laid down in the Declaration of Helsinki and all procedures were approved by the Institutional Review Board of the French Institute of Health and Medical Research (IRB INSERM; number 0000388FWA00005831) and the Commission Nationale Informatique et Libertés (CNIL; numbers 908450 and 909216). Written electronic informed consent to participate in the study was obtained from all subjects.

\section{Supplementary material}

To view supplementary material for this article, please visit http://dx.doi.org/10.1017/S1368980016001610

\section{References}

1. American Institute for Cancer Research/World Cancer Research Fund (2007) Food, Nutrition, Physical Activity and the Prevention of Cancer: A Global Perspective. Washington, DC: AICR.

2. World Health Organization (2003) Diet, Nutrition and the Prevention of Chronic Diseases. Joint WHO/FAO Expert Consultation. WHO Technical Report Series no. 916. Geneva: WHO.
3. Millward DJ \& Garnett T (2010) Plenary Lecture 3: Food and the planet: nutritional dilemmas of greenhouse gas emission reductions through reduced intakes of meat and dairy foods. Proc Nutr Soc 69, 103-118.

4. Chowdhury R, Stevens S, Gorman D et al. (2012) Association between fish consumption, long chain omega 3 fatty acids, and risk of cerebrovascular disease: systematic review and meta-analysis. BMJ 345, e6698.

5. Micha R, Wallace SK \& Mozaffarian D (2010) Red and processed meat consumption and risk of incident coronary heart disease, stroke, and diabetes mellitus: a systematic review and meta-analysis. Circulation 121, 2271-2283.

6. Ralston RA, Lee JH, Truby $\mathrm{H}$ et al. (2012) A systematic review and meta-analysis of elevated blood pressure and consumption of dairy foods. J Hum Hypertens 26, 3-13.

7. Soedamah-Muthu SS, Verberne LD, Ding EL et al. (2012) Dairy consumption and incidence of hypertension: a dose-response meta-analysis of prospective cohort studies. Hypertension 60, 1131-1137.

8. Laaksonen M, Talala K, Martelin T et al. (2008) Health behaviours as explanations for educational level differences in cardiovascular and all-cause mortality: a follow-up of 60000 men and women over 23 years. Eur J Public Health 18, 38-43.

9. Mejean C, Droomers M, van der Schouw YT et al. (2013) The contribution of diet and lifestyle to socioeconomic inequalities in cardiovascular morbidity and mortality. Int J Cardiol 168, 5190-5195.

10. Stringhini S, Sabia S, Shipley M et al. (2010) Association of socioeconomic position with health behaviors and mortality. JAMA 303, 1159-1166.

11. Darmon N \& Drewnowski A (2008) Does social class predict diet quality? Am J Clin Nutr 87, 1107-1117.

12. Dowler E (2001) Inequalities in diet and physical activity in Europe. Public Health Nutr 4, 701-709.

13. Galobardes B, Morabia A \& Bernstein MS (2001) Diet and socioeconomic position: does the use of different indicators matter? Int J Epidemiol 30, 334-340.

14. Turrell G, Hewitt B, Patterson C et al. (2003) Measuring socio-economic position in dietary research: is choice of socio-economic indicator important? Public Health Nutr $\mathbf{6}$, 191-200.

15. Galobardes B, Shaw M, Lawlor DA et al. (2006) Indicators of socioeconomic position (part 2). J Epidemiol Community Health 60, 95-101.

16. Galobardes B, Shaw M, Lawlor DA et al. (2006) Indicators of socioeconomic position (part 1). J Epidemiol Community Health 60, 7-12.

17. Braveman PA, Cubbin C, Egerter S et al. (2005) Socioeconomic status in health research: one size does not fit all. JAMA 294, 2879-2888.

18. Boylan S, Lallukka T, Lahelma E et al. (2011) Socioeconomic circumstances and food habits in Eastern, Central and Western European populations. Public Health Nutr 14, 678-687.

19. Hulshof KF, Brussaard JH, Kruizinga AG et al. (2003) Socioeconomic status, dietary intake and $10 \mathrm{y}$ trends: the Dutch National Food Consumption Survey. Eur J Clin Nutr 57, 128-137.

20. McCabe-Sellers BJ, Bowman S, Stuff JE et al. (2007) Assessment of the diet quality of US adults in the Lower Mississippi Delta. Am J Clin Nutr 86, 697-706.

21. Touvier M, Kesse-Guyot E, Mejean C et al. (2010) Variations in compliance with recommendations and types of meat/ seafood/eggs according to sociodemographic and socioeconomic categories. Ann Nutr Metab 56, 65-73.

22. Touvier M, Mejean C, Kesse-Guyot E et al. (2011) Sociodemographic and economic characteristics associated with dairy intake vary across genders. J Hum Nutr Diet 24, $74-85$. 
23. Hercberg S, Castetbon K, Czernichow S et al. (2010) The Nutrinet-Sante Study: a web-based prospective study on the relationship between nutrition and health and determinants of dietary patterns and nutritional status. BMC Public Health 10, 242.

24. Institut National de la Statistique et des Études Économique (2011) French national census data. http://www.insee.fr/fr/ bases-de-donnees/default.asp?page=recensements.htm (accessed November 2015).

25. Institut National de la Statistique et des Études Économique (2015) Definitions and methods: Consumption unit. http:// www.insee.fr/en/methodes/default.asp?page=definitions/ unite-consommation.htm (accessed November 2015).

26. Touvier M, Kesse-Guyot E, Mejean C et al. (2011) Comparison between an interactive web-based self-administered $24 \mathrm{~h}$ dietary record and an interview by a dietitian for largescale epidemiological studies. Br J Nutr 105, 1055-1064.

27. Le Moullec N, Deheeger M, Preziosi P et al. (1996) Validation du manuel photos utilisé pour l'enquête alimentaire de l'étude SU.VI.MAX. Cah Nutr Diet 31, 158-164.

28. Lassale C, Castetbon K, Laporte F et al. (2015) Validation of a web-based, self-administered, non-consecutive-day dietary record tool against urinary biomarkers. Br J Nutr 113, 953-962.

29. Lassale C, Castetbon K, Laporte F et al. (2015) Correlations between fruit, vegetables, fish, vitamins, and fatty acids estimated by web-based nonconsecutive dietary records and respective biomarkers of nutritional status. J Acad Nutr Diet 116, 427-438.e5.

30. Arnault N, Caillot L, Castetbon K et al. (2013) Table de Composition des aliments NutriNet-Santé. Paris: Editions Économica.

31. Hercberg S, Chat-Yung S \& Chauliac M (2008) The French National Nutrition and Health Program: 2001-2006-2010. Int J Public Health 53, 68-77.

32. Black AE (2000) Critical evaluation of energy intake using the Goldberg cut-off for energy intake:basal metabolic rate. A practical guide to its calculation, use and limitations. Int J Obes Relat Metab Disord 24, 1119-1130.

33. Schofield WN (1985) Predicting basal metabolic rate, new standards and review of previous work. Hum Nutr Clin Nutr 39, 5-41.

34. Black AE (1999) Small eaters or under-reporters? In Progress in Obesity Research. 8th International Congress on Obesity, pp. 223-228 [G Ailhaud and B Guy-Grand, editors]. Paris: John Libbey.

35. Pan Y \& Jackson RT (2008) Ethnic difference in the relationship between acute inflammation and serum ferritin in US adult males. Epidemiol Infect 136, 421-431.

36. Hu D, Huang J, Wang Y et al. (2014) Dairy foods and risk of stroke: a meta-analysis of prospective cohort studies. Nutr Metab Cardiovasc Dis 24, 460-469.

37. Kaluza J, Wolk A \& Larsson SC (2012) Red meat consumption and risk of stroke: a meta-analysis of prospective studies. Stroke 43, 2556-2560.

38. Soedamah-Muthu SS, Ding EL, Al-Delaimy WK et al. (2011) Milk and dairy consumption and incidence of cardiovascular diseases and all-cause mortality: dose-response meta-analysis of prospective cohort studies. Am J Clin Nutr 93, 158-171.

39. Deshmukh-Taskar P, Nicklas TA, Yang SJ et al. (2007) Does food group consumption vary by differences in socioeconomic, demographic, and lifestyle factors in young adults? The Bogalusa Heart Study. J Am Diet Assoc 107, 223-234.

40. Petkeviciene J, Klumbiene J, Prattala R et al. (2007) Educational variations in the consumption of foods containing fat in Finland and the Baltic countries. Public Health Nutr 10, 518-523.

41. Prattala R, Paalanen L, Grinberga D et al. (2007) Gender differences in the consumption of meat, fruit and vegetables are similar in Finland and the Baltic countries. Eur J Public Health 17, 520-525.

42. Maguire ER \& Monsivais P (2014) Socio-economic dietary inequalities in UK adults: an updated picture of key food groups and nutrients from national surveillance data. $\mathrm{Br} J$ Nutr 113, 181-189.

43. Wiig K \& Smith C (2009) The art of grocery shopping on a food stamp budget: factors influencing the food choices of low-income women as they try to make ends meet. Public Health Nutr 12, 1726-1734

44. Hoek AC, Luning PA, Stafleu A et al. (2004) Food-related lifestyle and health attitudes of Dutch vegetarians, non-vegetarian consumers of meat substitutes, and meat consumers. Appetite 42, 265-272.

45. Bonaccio M, Bonanni AE, Di Castelnuovo A et al. (2012) Low income is associated with poor adherence to a Mediterranean diet and a higher prevalence of obesity: crosssectional results from the Moli-sani study. BMJ Open 2, 6.

46. Worsley A, Blasche R, Ball K et al. (2003) Income differences in food consumption in the 1995 Australian National Nutrition Survey. Eur J Clin Nutr 57, 1198-1211.

47. Darmon N, Ferguson EL \& Briend A (2002) A cost constraint alone has adverse effects on food selection and nutrient density: an analysis of human diets by linear programming. J Nutr 132, 3764-3771.

48. Darmon N, Ferguson E \& Briend A (2003) Do economic constraints encourage the selection of energy dense diets? Appetite 41, 315-322.

49. Seiluri T, Lahelma E, Rahkonen O et al. (2011) Changes in socio-economic differences in food habits over time. Public Health Nutr 14, 1919-1926.

50. Sanchez-Villegas A, Martinez JA, Prattala R et al. (2003) A systematic review of socioeconomic differences in food habits in Europe: consumption of cheese and milk. Eur $J$ Clin Nutr 57, 917-929.

51. Groth MV, Fagt S \& Brondsted L (2001) Social determinants of dietary habits in Denmark. Eur J Clin Nutr 55, 959-966.

52. Smith AM \& Baghurst KI (1992) Public health implications of dietary differences between social status and occupational category groups. J Epidemiol Community Health $\mathbf{4 6}$, 409-416.

53. Kriaucioniene V, Klumbiene J, Petkeviciene J et al. (2012) Time trends in social differences in nutrition habits of a Lithuanian population: 1994-2010. BMC Public Health 12, 218.

54. Prattala RS, Groth MV, Oltersdorf US et al. (2003) Use of butter and cheese in 10 European countries: a case of contrasting educational differences. Eur J Public Health 13, 124-132.

55. Agence Française de Sécurité Sanitaire des Aliments (2009) Etude individuelle nationale des consommations alimentaires 2 (Inca2, 2006-2007). Maisons-Alfort: Afssa.

56. Castetbon K, Vernay M, Malon A et al. (2009) Dietary intake, physical activity and nutritional status in adults: the French nutrition and health survey (ENNS, 2006-2007). Br J Nutr 102, $733-743$.

57. Galea S \& Tracy M (2007) Participation rates in epidemiologic studies. Ann Epidemiol 17, 643-653.

58. Willett WC (1998) Nutritional Epidemiology. New York: Oxford University Press.

59. Brussaard JH, Lowik MR, Steingrimsdottir L et al. (2002) A European food consumption survey method - conclusions and recommendations. Eur J Clin Nutr 56, Suppl. 2, S89-S94. 